Supporting information

\title{
Microsuspension Polymerization of Styrene using Cellulose Nanocrystals as Pickering Emulsifiers: on the Evolution of Latex Particles
}

Joe Glasinga, Philip G. Jessopp , Pascale Champagne, ${ }^{\mathrm{a}, \mathrm{c}}$, Wadood Y. Hamad ${ }^{\mathrm{d}}$, Michael F. Cunninghamab*

a Department of Chemical Engineering, 19 Division Street, Queen's University, Kingston, ON K7L 3N6, Canada.

b Department of Chemistry, 90 Bader Lane, Queen's University, Kingston, ON K7L 3N6, Canada.

c Department of Civil Engineering, 58 University Avenue, Queen's University, Kingston, ON K7L 3N6, Canada.

d Transformation and Interfaces Group - Bioproducts ICE FPInnovations, 2665 East Mall, Vancouver, BC V6T 1Z4, Canada.

*Corresponding Author. Department of Chemical Engineering, 19 Division Street, Queen's University, Kingston, ON K7L 3N6, Canada.

E-mail: michael.cunningham@queensu.ca 


\section{EXPERIMENTAL}

Materials. Cellulose nanocrystals (CNC, sulfate sodium salt), provided by FPInnovations, were prepared by sulfuric acid hydrolysis of a commercial bleached softwood kraft pulp at FPInnovations CNC pilot plant (Pointe-Claire, Quebec). Copolymers of $N$-3-(dimethylamino) propyl methacrylamide (DMAPMAm) and styrene (S) as well as $N, N$-(diethylamino)ethyl methacrylate (DEAEMA) and S were grafted to $\mathrm{CNC}$ as previously reported. ${ }^{26}$ All chemicals and inhibitor removal columns were purchased from Sigma-Aldrich unless otherwise stated. Styrene was purified by passage through columns packed with inhibitor remover. APS, AIBN, 2-2'-azobis(2,4-dimethylvaleronitrile) (Vazo-52), Wako-Chemicals), lauroyl peroxide (LPO), nitrogen $\left(\mathrm{N}_{2}\right.$, Praxair, 99.999\%) and tetrahydrofuran (THF, $\geq 99 \%$ ) were used as received. Deionized water (DIW) from a Direct-Q 3 UV System (Millipore Corporation) had a resistivity of $18.2 \mathrm{M} \Omega \mathrm{cm}$.

Preparation of high and low internal phase emulsions for the microsuspension polymerization of styrene using native and graft-modified CNC as Pickering emulsifiers. Styrene emulsions stabilized by native $\mathrm{CNC}$ were prepared by diluting a high internal phase emulsion (HIPE). The HIPE was prepared as follows: styrene (23.6 g) containing the desired initiator (molar ratio S:I $=100: 1)$ and hexadecane $(0.7$ g) were added to a $50 \mathrm{~mL}$ round bottom flask and sparged with $\mathrm{N}_{2}$ for $5 \mathrm{~min}$ in an ice bath. In another flask, native CNC $(0.56 \mathrm{~g})$ were dispersed in DIW (14 g) using a sonication probe. The dispersion was sparged with $\mathrm{N}_{2}$ for $10 \mathrm{~min}$. The styrene solution and CNC dispersion were combined in a $100 \mathrm{~mL}$ beaker and homogenized with an IKA ${ }^{\circledR}$ T25 digital ULTRA-TURRAX ${ }^{\circledR}$ homogenizer following a two-step procedure in which the homogenization speed was set to $10,000 \mathrm{rpm}$ for 1 min to give a HIPE with $65 \mathrm{vol} \%$ styrene content and $1.5 \mathrm{wt} \%$ CNC. Next, $15.4 \mathrm{~mL}$ of the HIPE were diluted with DIW (24.6 mL) to give a low internal phase emulsion (LIPE, $40 \mathrm{~mL}$ ) with 25 vol\% styrene and $0.55 \mathrm{wt} \% \mathrm{CNC}$ (entries A1-A5). LIPEs for entries A6-A11 were prepared as follows: CNC-g-P(DMAPMAm- $\mathrm{co}-\mathrm{S}$ ) or CNC-gP(DEAEMA-co-S) $(0.215 \mathrm{~g})$ was dispersed in DIW $(30 \mathrm{~mL})$ by stirring and sonicating for 2 min at $\sim 3$ watts RMS using a microprobe sonicator (Fisher Scientific, Sonic Dismembrator). The dispersion was first sparged with $\mathrm{CO}_{2}$ for $10 \mathrm{~min}$ and sonicated for two minutes to ensure protonation of the tertiary amine groups and full dispersion of the grafted CNC in water. The dispersion was then sparged with $\mathrm{N}_{2}$ for $4 \mathrm{~min}$ at room temperature (in the case of CNC-g-(DMAPMAm- $c o-S)$ at $40{ }^{\circ} \mathrm{C}$ ). Styrene $(9.09 \mathrm{~g})$ containing the desired initiator (molar ratio $\mathrm{S}: \mathrm{I}=100: 1$ ) was sparged with $\mathrm{N}_{2}$ for 5 min in a separate flask, which was kept in an ice-bath, and then added to the $\mathrm{CNC}$ dispersion. The two phases were homogenized at $17,000 \mathrm{rpm}$ to give a stable LIPE with $25 \mathrm{vol} \%$ styrene content. All emulsions were kept in an ice-bath during homogenization to limit the temperature increase caused by the high shear force.

Microsuspension polymerization of styrene using native and graft-modified CNC as Pickering emulsifiers. The emulsions were inserted into a preheated oil bath at $80{ }^{\circ} \mathrm{C}$ and the reactions carried out for $5 \mathrm{~h}$ under $\mathrm{N}_{2}$ atmosphere without bubbling. The flow rate of gas sparging was approximately $90 \mathrm{~mL} / \mathrm{min}$ in all experiments. Monomer conversion was determined gravimetrically. During polymerization, 1-2 g samples were withdrawn from the reaction mixture and immersed immediately in an ice/water bath to stop polymerization and then dried under air for 2 days.

Separation of latex particles from microsuspension polymer. A combination of sedimentation and centrifugation at low speeds was used to separate the latex particles from the microsuspension beads for particle size and $\zeta$-potential analysis. The PS microsuspension was allowed to settle for 5 hours by sedimentation. The top aqueous layer $(2 \mathrm{~mL})$ containing the latex particles was removed using a pipette, transferred into a $5 \mathrm{~mL}$ vial and centrifuged at 3,500 rpm at room temperature for $15 \mathrm{~min}$. The top $1 / 3$ of the turbid supernatant was removed using a pipette and centrifuged again at 3,500 rpm for $15 \mathrm{~min}$. This procedure was repeated two more times and the resulting supernatant after 3 total cycles was considered to be the latex fraction of the PS microsuspension. 
Surfactant-free emulsion polymerization in the presence of native and graft-modified CNC. Polymerizations following a classical emulsion polymerization recipe were conducted as follows: an aqueous suspension $(2.25 \mathrm{~g}$ ) containing the well-dispersed native CNC, CNC-g-P(DMAPMAm-co-S) or CNC-g-P(DEAEMA-co-S) at concentration of $0.55 \mathrm{wt} \%$ in respect to the total mass of styrene/water and styrene $(0.68 \mathrm{~g})$ containing the desired initiator (molar ratio $\mathrm{S}: \mathrm{I}=100: 1)$ were added to a $5 \mathrm{~mL}$ roundbottom flask and sparged with $\mathrm{N}_{2}$ for $2 \mathrm{~min}$ in an ice bath. The flask was inserted into a preheated oil bath at $80{ }^{\circ} \mathrm{C}$ and the reactions carried out for $5 \mathrm{~h}$ under $\mathrm{N}_{2}$ with a reflux condenser attached to the flask.

Characterization. The molecular weight (MW) and MWD was determined by gel permeation chromatography (GPC) with a Waters 2960 separation module containing three Styragel columns coupled with a Waters 2960 differential refractive index detector. THF was used as the eluent with a flow rate of $0.3 \mathrm{~mL} \mathrm{~min}{ }^{-1}$. Average molar masses $M_{\mathrm{n}}$ and $Ð$ were derived from a calibration curve based on PS standards (Polymer Standard Service). The PS microbeads covered with CNC were dissolved in THF overnight and centrifuged at $6,000 \mathrm{rpm}$ for $20 \mathrm{~min}$ to precipitate the agglomerated CNC. The top $2 / 3$ of the transparent supernatant was removed using a pipette and centrifuged again at $6,000 \mathrm{rpm}$ for $20 \mathrm{~min}$. This procedure was repeated two more times and the resulting PS solution was filtered using a $0.05 \mu \mathrm{m}$ pore size syringe to avoid the injection of CNC into the GPC columns. The percentage of the latex and microsuspension polymer fraction was determined by peak deconvolution of the GPC chromatograms of the original PS suspension. The styrene microsuspension droplets were visualized using a BX51 Olympus microscope. The average droplet diameter was measured by image analysis of optical micrographs using "ImageJ" software. Polymer PSDs were measured with a Mastersizer 2000 (Malvern Instruments) using laser diffraction (LD) for suspension polymer and with a Malvern Zetasizer Nano ZS using dynamic light scattering (DLS) for isolated latex particles at $25{ }^{\circ} \mathrm{C}$. Electrophoretic mobility measurements of aqueous dispersion aliquots were performed at $25^{\circ} \mathrm{C}$ on a Malvern Zetasizer Nano ZS using a universal dip cell. SEM imaging was performed on the Western Nanofabrication Facility LEO/Zeiss 1540XB FESEM. Imaging was performed at either $0.3 \mathrm{keV}$ energy and $3 \mathrm{~mm}$ working distance with the InLens detector or $1 \mathrm{keV}$ energy and $4 \mathrm{~mm}$ working distance with the Everhart-Thornley detector. Samples were mounted on conductive carbon tape and coated with $3 \mathrm{~nm}$ of Osmium metal using the Filgen Osmium Plasma Coater in the Western Nanofabrication Facility.

\section{Synthesis of CNC-g-P(DMAPMAm-co-S) and CNC-g-P(DEAEMA-co-S)}

The materials were obtained from previously reported work. ${ }^{1}$ Detailed procures can be found below:

\section{SG1-mediated copolymerisation of DMAPMAm and styrene in bulk}

DMAPMAm (20.0 g, $0.117 \mathrm{~mol})$, styrene (1.22 g, $11.7 \mathrm{mmol})$, NHS-BlocBuilder (0.62 g, 1.3 $\mathrm{mmol})$, and SG1 (38 $\mathrm{mg}, 0.013 \mathrm{mmol})$ were added to a $50 \mathrm{~mL}$ three-neck round-bottom flask fitted with a reflux condenser, a nitrogen inlet and a thermometer. The flask was immersed in an ice-water bath and the mixture stirred and deoxygenated under nitrogen for $20 \mathrm{~min}$. The flask was introduced into a preheated oil bath at $80{ }^{\circ} \mathrm{C}$, representing time zero of the polymerisation. The reaction mixture was stirred at $300 \mathrm{rpm}$ under $\mathrm{N}_{2}$ for 1-3 $\mathrm{h}$, depending on the targeted molecular weight, with samples withdrawn periodically for kinetic studies and raw polymer analysis. Samples were quenched by immersion in an ice-water bath, precipitated in cold hexane and dried under air flow until constant mass was attained. To stop the polymerisation, the flask was cooled in an ice-water bath. P(DMAPMAm-co-S)-SG1 was purified using dialysis in 20-fold volume of hexane and obtained as a transparent, glassy polymer. P(DMAPMAm-co-S)-SG1 was analyzed by ${ }^{1} \mathrm{H}$ NMR and inverse gated (IG) ${ }^{13} \mathrm{C}$ NMR spectroscopy. ${ }^{1}$

\section{SG1-mediated copolymerisation of DEAEMA and styrene in bulk}

DEAEMA (20.0 g, $0.108 \mathrm{~mol})$, styrene (1.12 g, $10.8 \mathrm{mmol})$, NHS-BlocBuilder (0.57 g, 1.2 $\mathrm{mmol}$ ), and SG1 (35 mg, $0.12 \mathrm{mmol})$ were added to a $50 \mathrm{~mL}$ three-neck round-bottom flask fitted with a reflux condenser, a nitrogen inlet and a thermometer. The rest of the procedure follows the 
aforementioned for P(DMAPMAm-co-S)-SG1. The macroalkoxyamines were purified by precipitation and dialysis in 20-fold volume of diethyl ether and yielding a white paste. P(DEAEMA-co-S)-SG1 was analyzed by SEC and ${ }^{1} \mathrm{H}$ NMR spectroscopy. ${ }^{1}$

\section{Modifying CNC with glycidyl methacrylate (GMA)}

In a three neck round bottom flask, CNC ( $1 \mathrm{~g}$ of solids, $6.2 \mathrm{mmol}$ of total hydroxyls) was dissolved in $100 \mathrm{~mL} 0.4 \mathrm{M}$ acetic acid and sonicated for $20 \mathrm{~min}$ until the CNCs were completely dispersed. Next, $\mathrm{KOH}(5 \mathrm{~mL}, 0.05 \mathrm{M})$ and hydroquinone $\left(10 \mathrm{~mL}, 9.09 \times 10^{-5} \mathrm{~mol}\right)$ were added to the flask. The reaction mixture was degassed with nitrogen for $30 \mathrm{~min}$ and subsequently immersed into an oil bath preheated to $65^{\circ} \mathrm{C}$. Glycidyl methacrylate (GMA) (3.53 g, $\left.24.8 \mathrm{mmol}\right)$ was added to the system dropwise using a $100 \mathrm{ml}$ dropping funnel. The mixture was magnetically stirred for $2 \mathrm{~h}$ at $65^{\circ} \mathrm{C}$. The reaction system was cooled down with an ice bath and the product was separated from the acid medium by centrifugation. The supernatant was decanted and the GMA modified was redispersed into $60 \mathrm{ml}$ of methanol and vigorously stirred for $1 \mathrm{~h}$ at room temperature to remove unreacted GMA. The purification was repeated three times. The particles were analyzed by FT-IR and ${ }^{13} \mathrm{C}$ CP-MAS NMR spectroscopy and TGA. ${ }^{1}$

\section{Grafting to reaction of P(DMAPMAm-co-S)-SG1 and P(DEAEMA-co-S)-SG1 to GMA modified CNC}

In a $100 \mathrm{ml}$ three neck flask, $3 \mathrm{~g}$ of GMA modified CNC (wet cake, about $0.21 \mathrm{~g}$ of solids) was suspended in $45 \mathrm{ml}$ of DI water and subjected to sonication for $20 \mathrm{~min}$. The flask was fitted with a reflux condenser, a nitrogen inlet and a dropping funnel and the dispersion stirred and purged with $\mathrm{N}_{2}$ for $20 \mathrm{~min}$. In a second $50 \mathrm{ml}$ round bottom flask, $0.8 \mathrm{~g}$ of dried P(DMAPMAm-co-S)SG1 was dissolved in $30 \mathrm{ml}$ of deionized water (DIW), and the solution deoxygenated for $30 \mathrm{~min}$. The solution was then transferred into the dropping funnel and degassed throughout the reaction. The reaction flask was transferred to an oil bath preheated to $85^{\circ} \mathrm{C}$ and $10 \mathrm{ml}$ of the macroalkoxyamine solution was added through the dropping funnel. After 30 and 60 min, another $10 \mathrm{ml}$ was added and the system was allowed to react further for $2 \mathrm{~h}$. The reaction was quenched in an ice bath and the modified CNC particles separated from the solvent by centrifugation. The precipitate was washed with $60 \mathrm{ml}$ of THF by stirring in a beaker for $20 \mathrm{~min}$ and then subjected to ultrasound for another $30 \mathrm{~min}$. The modified CNC particles were collected by centrifugation. To ensure the absence of free polymer, exhaustive product purification with repeated centrifugation/redispersion cycles was performed 4 times. The procedure for the synthesis of CNC-g-P(DEAEMA-co-S) followed the aforementioned for CNC-g-P(DMAPMAm-co-S), with the exception that P(DEAEMA-co-S)-SG1 was dissolved in $30 \mathrm{ml}$ of $0.4 \mathrm{M}$ acetic acid. CNC- $g$ P(DEAEMA-co-S) and CNC-g-P(DMAPMAm-co-S) particles were analyzed by ${ }^{13} \mathrm{C}$ CP-MAS NMR and FT-IR spectroscopy, TGA and EA. ${ }^{1}$ 
Table S1 Polymer content, graft molecular weight, copolymer composition, graft density and total amount of amine groups per one gram of CNC for CNC-g-P(DMAPMAm-co-S) and CNC-g-P(DEAEMA-co-S) batches.

\begin{tabular}{|c|c|c|c|c|c|}
\hline Sample & $\begin{array}{c}\text { Polymer } \\
\text { content } a \\
{[\mathrm{wt} \%]}\end{array}$ & $\begin{array}{c}\text { Graft } \\
M_{\mathrm{n}} \\
{[\mathrm{g} / \mathrm{mol}]}\end{array}$ & $\begin{array}{c}\text { Styrene } \\
\text { content } a \\
{[\%]}\end{array}$ & $\begin{array}{l}\text { Graft density } \\
\quad \times 10^{-2} \\
{\left[\text { chains } / \mathrm{nm}^{2}\right]}\end{array}$ & $\begin{array}{c}\text { Amine groups } \\
{[\mathrm{mmol} / \mathrm{g}]}\end{array}$ \\
\hline CNC-g-P(DMAPMAm- $c o-S)$ & 18 & $4400^{b}$ & 16 & 5.2 & 0.91 \\
\hline CNC-g-P(DEAEMA-co-S) & 20 & $4200^{c}$ & 11 & 6.2 & 1.12 \\
\hline
\end{tabular}

${ }^{a}$ Determined by elemental analysis. ${ }^{b}$ Determined by ${ }^{1} \mathrm{H}$ NMR spectroscopy. ${ }^{\mathrm{c}}$ Determined by GPC. ${ }^{1}$

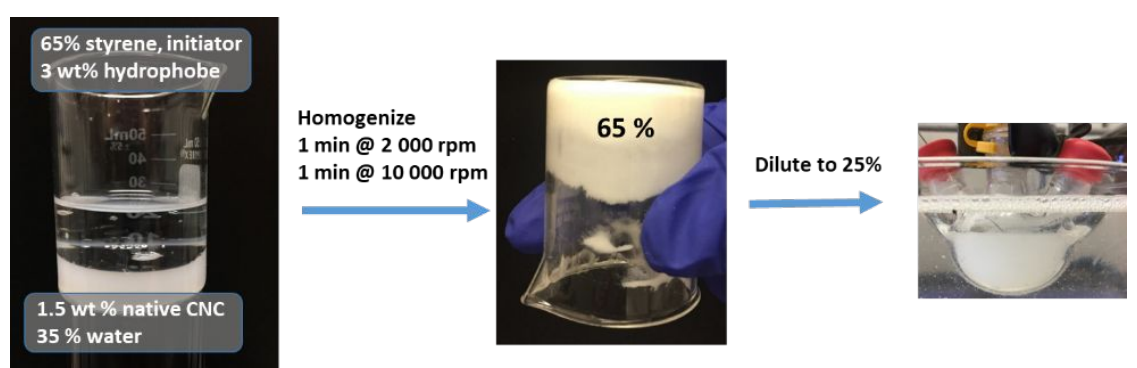

Figure S1 General procedure to make a HIPS consisting of 65 vol $\%$ styrene, $3 \mathrm{wt} \%$ hydrophobe and 35 vol $\%$ water using 1.5 $\mathrm{wt} \%$ native CNC (in respect to total mass of HIPS) and dilute to a $20 \%$ styrene LIPS.
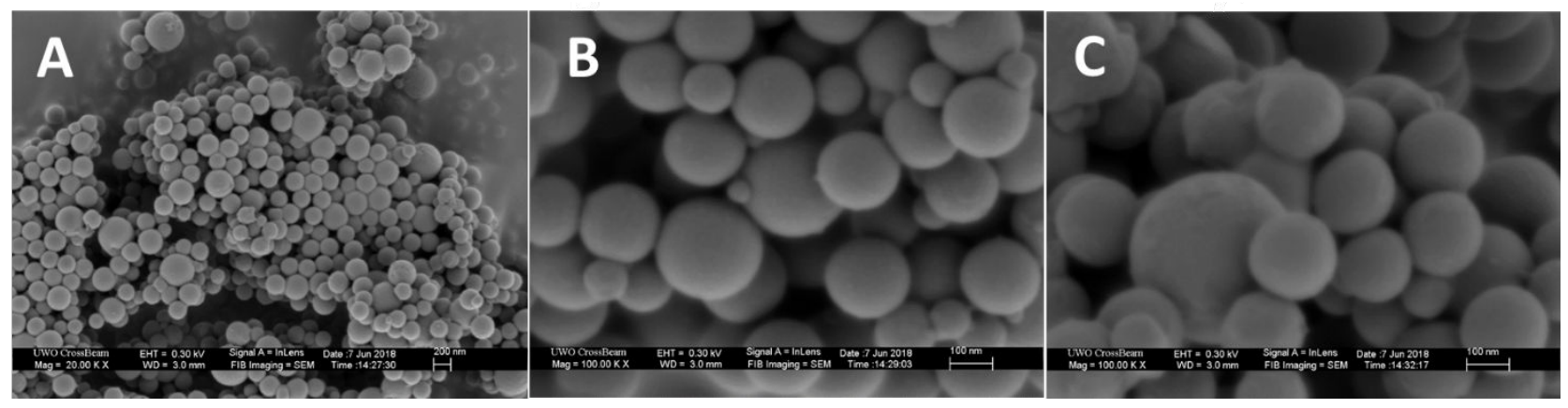

Figure S2 Latex particles from entry A1 separated from microsuspension polymer by centrifugation, lacking the presence of CNC.

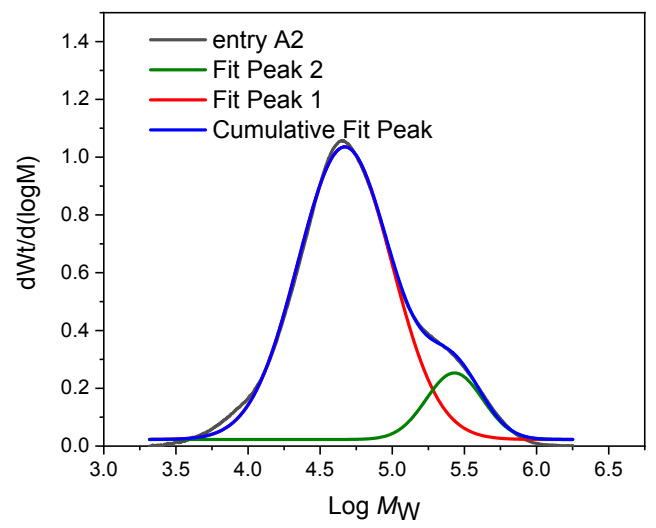

Figure S3 Determination of emulsion polymer for entry A2 by peak deconvolution. 
Entry A4
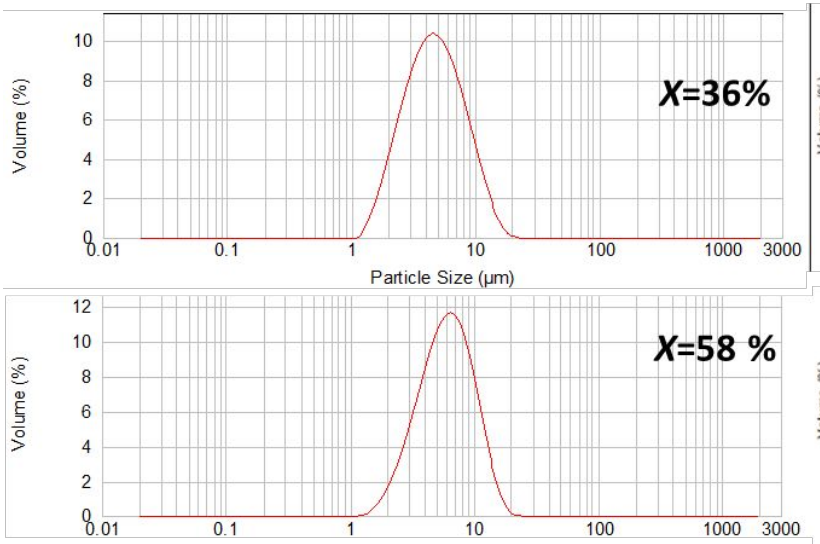

Entry A1
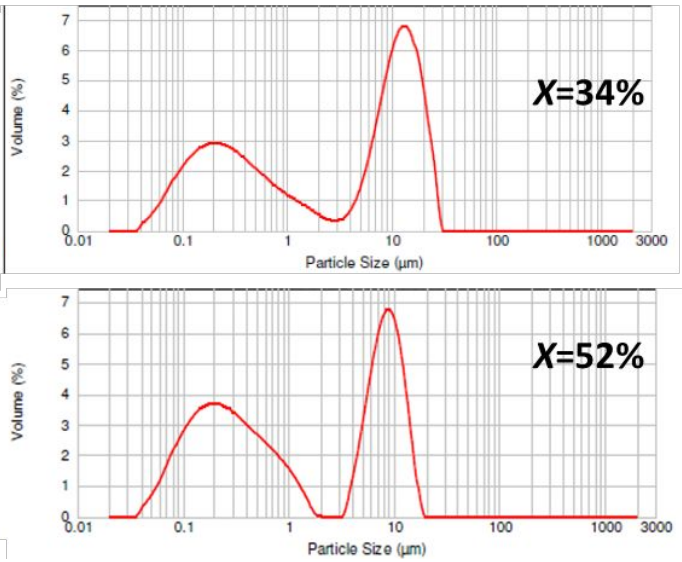

Figure S4: Evolution of polystyrene particle diameter distribution (volume average) of entry A1 and A4 at 36\% and 34\% as well as $58 \%$ and $52 \%$ conversion.
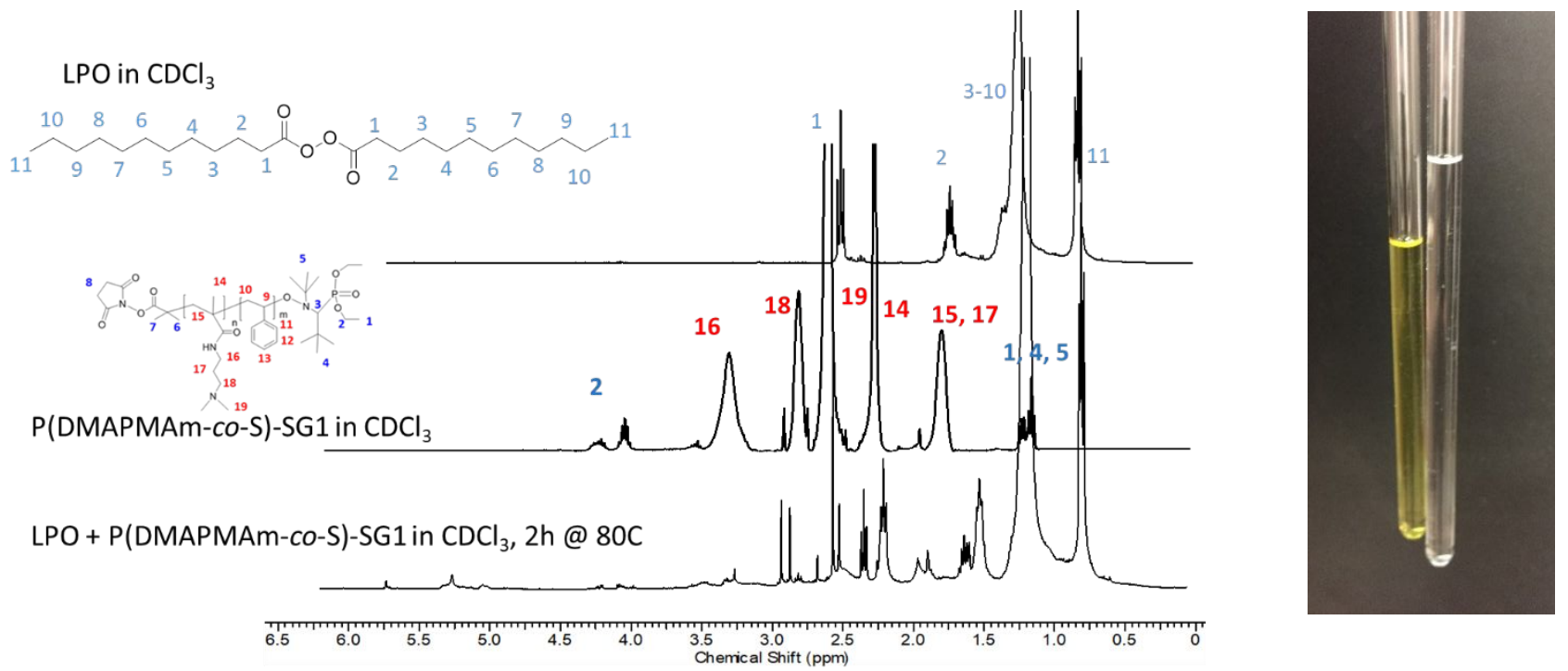

Figure S5: Left: ${ }^{1} \mathrm{H}$ NMR (400.30 MHz, $\mathrm{CDCl}_{3}$ ) spectra of LPO (top) and P(DMAPMAm-co-S)-SG1 (middle) after dissolving in $\mathrm{CDCl}_{3}$ at room temperature, and after stirring $\mathrm{LPO}$ and $\mathrm{P}(\mathrm{DMAPMAm}-\mathrm{co}-\mathrm{S})-\mathrm{SG} 1$ in $\mathrm{CDCl}_{3}$ at $80{ }^{\circ} \mathrm{C}$ for $2 \mathrm{~h}$ (bottom). Right: Picture of the NMR tubes of P(DMAPMAm-co-S)-SG1 in $\mathrm{CDCl}_{3}$ (transparent) and after stirring LPO and P(DMAPMAm-co-S)SG1 in $\mathrm{CDCl}_{3}$ at $80{ }^{\circ} \mathrm{C}$ for $2 \mathrm{~h}$.

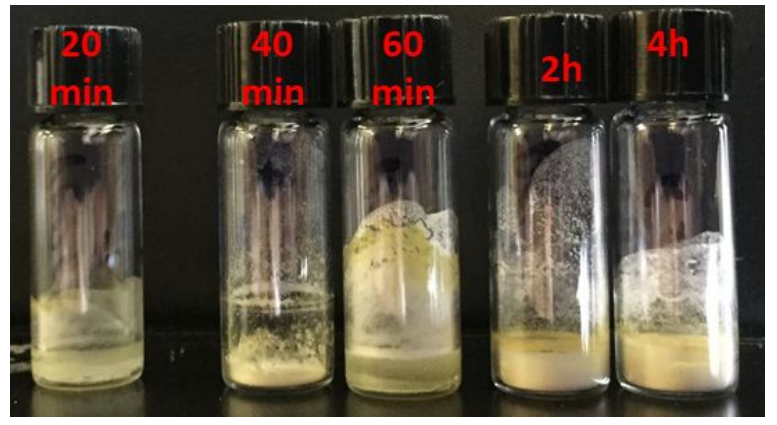

Figure S6 Microsuspension from entry A8 showing the presence of the yellow oxidation product throughout the polymerization. 


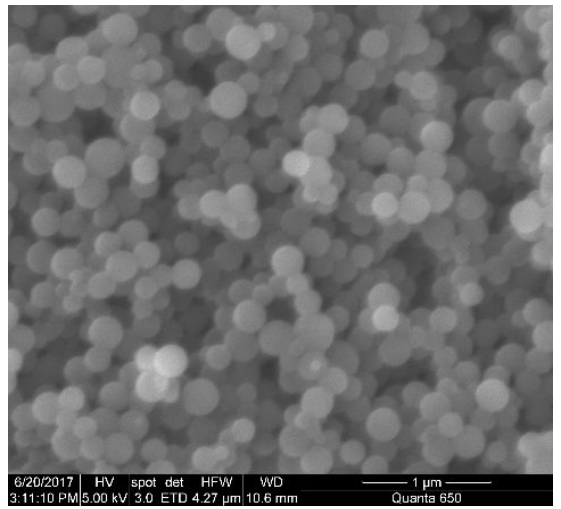

Figure S7 SEM micrograph of SFEP particles obtained from entry A5 stabilized by KPS, lacking the presence of CNC.

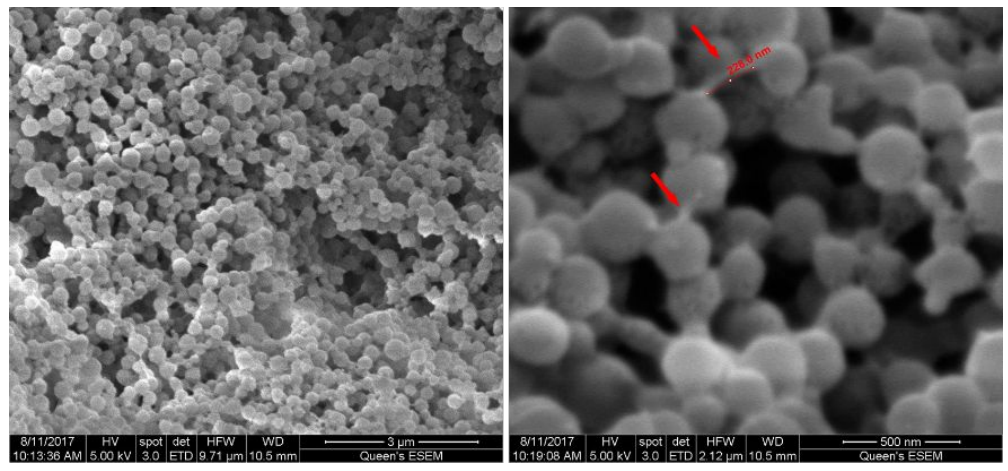

Figure S8 SEM Micrographs of SFEP particles from entry B2 exhibiting 'free' CNC dispersed among the emulsion polymer particles.
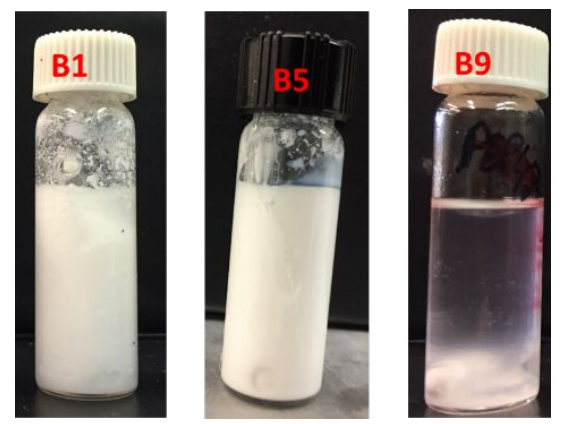

Figure S9 Pictures of entries B1, B5 and B9 after $5 \mathrm{~h}$ of polymerization exposing a white coagulum for entry B1, a stable SFEP latex for entry B5, and transparent coagulum for entry B9.

\section{References}

1 J. Glasing, J. Bouchard, P. G. Jessop, P. Champagne and M. F. Cunningham, Polym. Chem., 2017, 8, 6000-6012. 